\title{
Crip Times: Disability, Globalization, and Resistance
}

\section{Autor: Robert McRuer}

Páginas: 283

Editorial: New York University Press (NYU), 2018

Ciudad: New York

El teórico estadounidense Robert McRuer en su último libro Crip Times, Disability, Globalization, and Resistance extiende los planteamientos de su obra Crip Theory (2006) y emprende la tarea de teorizar la discapacidad como un tema nuclear de la estrategia económica y cultural de la austeridad, administrada tras la crisis mundial de 2008, en el marco del sistema capitalista neoliberal. El autor toma varios ejemplos geopolíticos de campañas activistas que apuntalan el carácter globalizado de los tiempos crip. Sin embargo, el texto se focaliza en Reino Unido para "tullir» ("to crip») la austeridad, esto es, destapar la centralidad de la (dis)capacidad oculta en el neoliberalismo y en el diseño y ejecución de las políticas de recortes llevadas a cabo por la coalición Tory-Lib Dems durante el mandato de David Cameron (2010-2016).

Retomando su libro Crip Theory, McRuer postuló en él un sistema disciplinario de normalización que denominó "capacidad obligatoria» ["compulsory able-bodiedness»] basándose en los conceptos de "heterosexualidad obligatoria» y de "performatividad" de las teóricas queer Adrienne Rich (1983) y Judith Butler (1990) respectivamente. Este sistema, ligado al auge del capitalismo industrial y al cuerpo capaz productivo e intersecado con el sistema de la heterosexualidad obligatoria, sería el motor de la (re)producción de las identidades corporales esencializadas y naturalizadas de la (dis)capacidad. Por ello, frente al Modelo Médico, en donde la discapacidad es biopolíticamente tratada como una desviación y falla individual física, psíquica y/o sensorial, y frente al Modelo Social, en donde la causa de la misma se traslada a un conjunto social opresor de la diversidad de cuerpos-mentes (Oliver, 1990), McRuer nos ofrece lo crip como un Modelo Cultural de la misma que es políticamente radical y revo-

\footnotetext{
* Correspondencia a / Correspondence to: Carlos García Grados. Universidad del País Vasco/Euskal Herriko Unibertsitatea, Departamento de Sociología 2. Barrio Sarriena, s/n (48940-Leioa) - carlos.garciagr@ehu.eus - http://orcid.org/0000-0003-4692-6864.

ISSN 1695-6494 / @ 2020 UPV/EHU
} 
lucionario, en lugar de asimilacionista o reformista. La discapacidad es aquí una categoría de representación de los cuerpos abyectos.

La palabra crip, procedente del vocablo inglés cripple (deficiencia de alguna extremidad y también dificultad de movilidad), ha denotado históricamente estigma y burla. Sin embargo, como ha sucedido con la palabra queer, activistas y artistas anglosajones del movimiento de la discapacidad se han reapropiado del término para neutralizar jocosamente su ofensa y convertirlo con orgullo en un sello simultáneo de identidad y anti-identidad colectiva que desafíe la imposición de normas, etiquetas y discursos capacitistas que tratan de contener a sus cuerpos. No obstante, a pesar de su relación original con la deficiencia física, el concepto crip excede la dicotomía capacidad/discapacidad para referirse también a aquellas constituciones y estados mentales-corporales que difícilmente son percibidos bajo el rubro habitual de la discapacidad (Kafer, 2013). Para el autor, crip pretende ser por tanto una herramienta de análisis, como lo es el género para el feminismo, que permita hacer perceptible elementos de la discapacidad imbuidos en fenómenos que en principio poco o nada parecen tener que ver con aquellos (McRuer, 2015).

La idea principal en Crip Times es que las lógicas del capitalismo neoliberal y de la austeridad, para perpetuarse y legitimarse, han recurrido insistentemente al uso de la discapacidad en un doble sentido: desplegando una retórica anti-discapacidad para justificar los recortes en gasto social y, complementariamente, seleccionando y espectacularizando representaciones e identidades excepcionales de la misma para velar tales recortes, sus efectos demoledores y las reacciones colectivas de protesta que incitan. El neoliberalismo, en aras de su no intervención en el flujo de capitales y de su continua búsqueda de nuevos nichos de mercado, prescribe y anima un individuo ideal autocontenido con espíritu de lucha y con capacidad de competir, de elegir libremente y de ser auto-responsable. Prueba de ello son campañas políticas conservadoras como la de Cameron "Broken Britain», en donde la causa de la crisis socio-económica se imputa al comportamiento de los individuos y no al propio sistema. Así, todo ser humano incapaz de satisfacer tales competencias de manera autónoma e independiente será etiquetado como un "otro" discapacitado que marca el límite exterior de la propia humanidad, lo que le arroja a la exclusión y le predispone a los mayores abusos en nombre de la acumulación de capital. El neoliberalismo niega y denosta la vulnerabilidad y la interdependencia humana, por tanto, es estructuralmente capacitista. Tanto es así que, desde el Thatcherismo y con más ahínco durante el Cameronismo, las personas receptoras de ayuda económica y social del Estado son estigmatizadas públicamente como scroungers, spongers o shirkers (gorrones, parásitos o gandules, en castellano), lo que además, según la lectura marxista de McRuer y atendiendo a la obra Chavs de Owen Jones (2011), ha servido como una estrategia efectiva que desvía la atención de la retórica de clases.

Otro de los argumentos destacables en Crip Times es que el contundente movimiento activista y artístico crip de resistencia y contestación mundial frente a las representaciones y retóricas neoliberales demuestra, por sí mismo, la centralidad de la discapacidad. La pretensión de estos movimientos es tullir, retorcer o hacer extraña aquella discapacidad que el neoliberalismo y la austeridad materializan para sostenerse y así producir su consiguiente desestabilización. Como ya he señalado, el movimiento crip abraza la identidad y la anti-identidad al mismo tiempo; no permite etiquetas procedentes del exterior a un nosotras/os que, a su vez, tampoco prescribe una identidad única, sino que esta permanece abierta para generar alianzas entre cuerpos diversos, dar cabida a lo radical y alentar nuevas formas de estar jun- 
tos. Ahora bien, una advertencia importante: el capitalismo puede integrar la diferencia convirtiéndola en uno de sus múltiples nichos, como demuestran en el texto las campañas de marketing dirigidas directa o indirectamente a consumidores gays. Sin embargo, a diferencia de la merma en el potencial radical de lo queer derivada de su mercantilización global, para McRuer la discapacidad y lo crip conservan aún hoy una mayor «promesa o posibilidad crítica».

Crip Times, como se refiere el autor, expresa tiempos, y también espacios, duros y difíciles que han generado nuevas formas de existencia. El tiempo de lo crip ha dado lugar a una colectividad radical transnacional nunca antes conformada, cuya finalidad, mediante la ubicación de la multiplicidad de mentes-cuerpos al frente y en el centro de la acción política, es tullir y resistir las espacio-temporalidades de una austeridad neoliberal globalizada que construye y produce cultural y materialmente la discapacidad. Esta es la "debris» ["detritus», en castellano] principal de un libro que se estructura a través de cuatro capítulos y cuatro palabras clave. Los dos primeros capítulos se focalizan en torno al activismo crip y a los términos "desposesión» y "resistencia». Los capítulos tercero y cuarto, en cambio, dan paso al arte crip y giran alrededor de las palabras «desplazamiento" y «aspiración» respectivamente.

En el primer capítulo, el autor expone dos representaciones culturales contrapuestas de la discapacidad para mostrar las intervenciones crip en el contexto británico de los Juegos Paralímpicos de Londres 2012 y de la ola de protestas del movimiento de la discapacidad en contra de los recortes. La primera se compone de dos imágenes: el meme del atleta con doble amputación de piernas Oscar Pistorious junto a una niña británica con amputación de piernas y manos. Ambos llevan prótesis para correr y, en actitud de carrera, la escena se acompaña de la sentencia "The only disability in life is a bad attitude». Y de un cartel publicitario paralímpico, en donde atletas con diferentes discapacidades perceptibles posan detrás del eslogan «Meet the superhumans». La segunda pertenece a la campaña activista crip «This is what disability looks like" (en adelante, "TIWDLL»), en donde personas con discapacidades, perceptibles o no, pusieron sus propios retratos en circulación por las redes sociales para resistir y combatir a las primeras. El primer conjunto de imágenes ejemplifica la estrategia política cultural neoliberal que McRuer denomina «austerity of representation». Dicha estrategia supone la selección y espectacularización, a veces melodramática, de unas identidades discapacitadas no amenazantes, domesticadas, que previenen representaciones e identidades crip más radicales, su sociabilidad y ocultan tanto el activismo y las acciones de protesta, como los estragos de la austeridad entre las personas con discapacidad y los abusos del capitalismo neoliberal. Además, la austeridad de representación explota a la persona con discapacidad como objeto de inspiración para alivio de los capacitados, lo que se ha denominado "cripspiration» (Willitts, 2012) o "inspiration porn» (Young, 2012), e individualiza y naturaliza la discapacidad bajo el discurso capacitista de la tragedia y la superación personal que tan bien representa la figura del supercrip. En este sentido, la palabra clave "desposesión» no solo atañe al expolio material de la vida de las personas con discapacidad sino también al bloqueo de nuevas subjetividades y sociabilidades crip. Por el contrario, el segundo grupo de imágenes promueve la apertura de lo que McRuer se refiere como «horizonte crip». La campaña "TIWDLL" implica una sociabilidad que no prescribe una identidad unívoca sino que es colectivamente contrarepresentativa o desidentificativa. Esta forma de activismo abre la posibilidad de una coalición alternativa entre cuerpos que potencie la expansión de aquello que puede significar la discapacidad. La desposesión, por tanto, se refiere ahora a una despose- 
sión crítica crip, atenta a las estructuras sociales y económicas, que invita a una salida de sí mismo para llevar a cabo una acción política con otros que resista las identidades neoliberales y genere nuevas subjetividades.

Al hilo de la campaña "TIWDLL» y apuntalando la sociabilidad crip, McRuer expone en el segundo capítulo otras seis tácticas de resistencia encarnada haciendo una lectura crip de varios ejemplos procedentes de diferentes lugares, siendo el primero de ellos, en el espacio de la abstracción, la propia teorización del concepto de resistencia. En segundo lugar, basado en el movimiento de personas con discapacidad CUIDO acontecido en Berkeley, California (EE.UU.), presenta la táctica del «crip camp» en conexión con la acampada del movimiento de Los Indignados en la Puerta del Sol (Madrid, España). A continuación, viaja hasta Chile para presentar las "huelgas de hambre» llevadas a cabo por el movimiento de estudiantes como táctica de protesta frente a la precariedad del sistema de educación. De vuelta en España, la cuarta táctica es la "objeción de conciencia» ejemplificada en el personal sanitario que se abstuvo de obedecer el Real Decreto Ley 16/2012 que impulsó el Partido Popular para negar la atención médica a inmigrantes ilegales. La táctica número cinco, de corte más clásico, es la apertura masiva de "Centros Médicos Sociales» en Grecia tras los efectos de la intervención europea de la «troika». Por último, devolviéndonos al Reino Unido, la sexta táctica es la "apropiación» y la «teatralización» de discursos dominantes. Esta táctica, originalmente queer, la ejemplifica a través de una instantánea de la campaña "TIWDLL" y de la impactante fotografía "Left Out in the Cold» de la artista crip Kaliya Franklin para la campaña "Broken of Britain».

Ahora en el terreno del arte, McRuer ofrece en el tercer capítulo una perspectiva crip de la obra fotográfica de Livia Radwanski, incluida en el Museo de los Desplazados, para mostrar el desplazamiento de las personas que habitan el inmueble Mérida 90 en Colonia Roma (Ciudad de México) y dar testimonio de su resistencia frente al proceso de gentrificación. Tal proceso ha sido enmascarado con una accesibilidad que, en realidad, entraña únicamente la ruptura de aquellas barreras que limitan la relación y los movimientos comerciales entre Reino Unido y México. El capítulo desvela que el resplandor de los Juegos Paralímpicos de 2012 en materia de accesibilidad ha sido utilizado como vehículo para la exportación en la Ciudad de México de una "política de la discapacidad anglo-imperial» que ha disimulado los efectos de la austeridad en materia de vivienda, el desahucio de muchas personas con discapacidad y la consecuente actividad de protesta durante la era Cameron. La excusa de una "Ciudad de México para todas y todos", atendiendo a la estrategia británica y ejemplificada en el gesto urbanístico de rebajar las aceras, ha servido para transformar áreas urbanas como Colonia Roma en espacios más atractivos para gente rica y para la inversión, lo que ha llevado aparejado la expulsión de aquellos cuerpos que obstaculizan dicha atracción y que no tienen la capacidad económica de permitirse vivir en el espacio renovado. Como concluye McRuer, los desplazamientos son siempre desplazamientos de la discapacidad.

En el cuarto y último capítulo McRuer hace una novedosa lectura crip de la retórica capacitista de las y los arquitectos del neoliberalismo gestado en el Reino Unido desde los años 70, con el fin de retratar el concepto hegemónico de "aspiración» que dicha retórica perfila y contrastarlo con aquella otra "aspiración» que emana de la performance de la artista y activista crip Liz Crow titulada "Figures» [léase figuras, pero también cifras o números, en castellano] (véase la imagen de la portada del libro de McRuer). 
Desde el discurso "Let Our Children Grow Tall» pronunciado en Nueva York en 1975 por Margaret Thatcher, pasando por el connivente mandato laboralista de Tony Blair y llegando hasta los días de David Cameron, también denominados Blameronismo, el término "aspiración» "ha sido básicamente codificado en la era del capitalismo neoliberal como un concepto individualista y libertario orientado hacia el logro personal y el mérito" ( $p$. 176). McRuer, además, añade que ueste sentido de la aspiración es ahora de muchas maneras obligatorio; asegura el consentimiento del orden político y económico dominante, divide a la gente y cortocircuita cualquier tipo de análisis de clase» (p. 176). Así, todo aquel que no haya podido o se haya negado a integrar el nuevo consenso social de la aspiración ha sido figurado como discapacitado desde el último tercio del siglo xx. Frente a ello, la aspiración de la obra de arte público de Crow es a la «totalidad». Las 650 figuras itinerantes modeladas con barro de las orillas del Támesis representan a las personas que han perecido a causa de la política de austeridad británica. No obstante, la imposibilidad de reconocer una única identidad en las figuras permite que todas aquellas personas afectadas por los recortes, discapacitadas o no, puedan identificar sus historias con la obra de Crow, lo que invita a la unión y a imaginar una sociabilidad crip alternativa que resista la austeridad. Figures, por tanto, plantea una epistemología crip para tullir el neoliberalismo y sus políticas austeras, es decir, incluye de manera ineludible el punto de vista de la discapacidad para poder así aspirar al abordaje de la totalidad. Como dice McRuer haciéndose eco de los estudios de la discapacidad: «todo el mundo será discapacitado si vive lo suficiente», por lo que de igual manera «toda revolución será crip si vive lo suficiente» (p. 129-130).

Crip Times, Disability, Globalization, and Resistance demuestra con argumentos ricos y convincentes su tesis principal acerca de la discapacidad como eje central del capitalismo neoliberal y de la austeridad globalizada. Aunque merecería la pena reflexionar si quizás el peso argumentativo que recae en el colectivo crip para demostrar tal hecho no tiene algo del porno inspiracional que precisamente McRuer critica. Por otro lado, el texto aporta un excelente ejemplo aplicado de la Teoría Crip que evidencia la potencialidad de lo crip como una herramienta de análisis cultural de la discapacidad que hace perceptible el (dis)capacitismo que la modernidad ha desplegado históricamente para su implantación y desarrollo. Lo que ha enriquecido el campo de los Disability Studies y ha ampliado el horizonte de los análisis interseccionales que, hasta ahora, tomaban en cuenta otros sistemas jerárquicos de organización como el género, la raza o la clase social. Un buen ejemplo de intersección de estos ejes son las alianzas Crip-Queer, así como también el incipiente cruce entre el giro animal en ciencias sociales y los estudios de la discapacidad (Taylor, 2017). Crip Times, por tanto, trata de instruirnos en la tarea de hacer lecturas crip de muy diversas realidades, aunque el autor, en ocasiones, peca de excesos interpretativos que suelen ir precedidos de una explicita impresión poética de aquellas escenas que analiza. No obstante, muy importante, también nos orienta hacia cómo estar alerta y resistir la austeridad representacional y, por tanto, a cómo detectar y combatir los excesos de las políticas de austeridad y del neoliberalismo global que inciden con contundencia particular sobre las personas con discapacidad, lo que sin duda es y será de gran utilidad ante crisis que con gran certeza, como alimento básico del capitalismo, regresarán en un futuro no muy lejano. 


\section{REFERENCIAS}

Butler, J. (1990). Gender Trouble: Feminism and the Subversion of Identity. New York: Routledge.

Jones, O. (2011). Chavs. The Demonization of the Working Class. London: Verso Books.

Kafer, A. (2013). Feminist, Queer, Crip. Bloomington: Indiana University Press.

McRuer, R. (2015). Tiempos Cripp: Discapacidad, Globalización y Resistencia. Conferencia magistral del VII Congreso de Ciencias, Artes y Humanidades: Cuerpos excluidos. Prácticas corporales y discriminación. Disponible en: https://www.youtube.com/watch?v=Q6f$97 \mathrm{Mz} 1 \mathrm{SE}$

McRuer, R. (2006). Crip Theory, Cultural Signs of Queerness and Disability. New York: New York University Press.

Oliver, M. (1990). The politics of disablement. Basingstoke: Macmillan.

Rich, A. (1983). Compulsory Hetersosexuality and Lesbian Existence. En A. Snitow, C. Stansell, $\&$ S. Thomson (Eds.), Powers of Desire: The Politics of Sexuality (pp. 177-205). New York: Monthly Review.

Taylor, S. (2017). Beast of Burden. Animal and Disability Liberation. New York: The New Press.

Willitts, P. (2012). Bad attitudes do not cause disability any more than good attitudes guarantee health. The Independent, 1 de agosto. Disponible en: https://blacktrianglecampaign. org/2012/08/02/bad-attitudes-do-not-cause-disability-any-more-than-goodattitudes-guarantee-health/.

Young, E. (2012). We're Not Here for Your Inspiration. Ramp Up, 2 de julio. Disponible en: https://www.abc.net.au/rampup/articles/2012/07/02/3537035.htm 